\title{
EFEITO DO ESTRESSE SALINO SOBRE O CRESCIMENTO E DESENVOLVIMENTO DE PLANTAS DE Physalis angulata $\mathrm{L}$.
}

\author{
Karolini da Silva Cruz ${ }^{1}$; Tamara Torres Tanan ${ }^{2}$ e Marilza Neves do Nascimento ${ }^{3}$ \\ 1. Bolsista PROBIC/UEFS, Graduando em Agronomia, Universidade Estadual de Feira de Santana, e-mail: \\ karlsilvacruz@hotmail.com \\ 2. Participante do projeto, Programa de Pós-Graduação em Recursos Genéticos Vegetais, Universidade Estadual de \\ Feira de Santana, e-mail: tamara.tanan@ yahoo.com.br \\ 3. Orientadora, Departamento de Ciências Biológicas, Universidade Estadual de Feira de Santana, e-mail: \\ marilzaagro@hotmail.com
}

PALAVRAS-CHAVE: solução salina; taxa de crescimento, clorofila, cloreto de sódio.

\section{INTRODUÇÃO}

A família Solanaceae inclui uma vasta variedade de plantas economicamente e farmacologicamente importante como a Physalis angulata L., também conhecida como camapú. A espécie destaca-se pela presença de metabólitos poli-oxigenados que possui grande interesse farmacológico. Além disso, apresenta fruto de sabor adocicado com bom conteúdo de vitaminas A e C, ferro e fósforo (Rufato et al. 2008).

No Brasil, aproximadamente nove milhões de hectares são afetados pela presença de sais, cobrindo sete Estados, com a maior área afetada localizada na Bahia (44\% do total) (Gheyi \& Fageria, 1997). A salinidade na rizosfera acarreta redução na permeabilidade das raízes para água, dando origem ao estresse hídrico, podendo exibir um impacto negativo substancial no crescimento e desenvolvimento das plantas (Lecoeur \& Sinclair, 1996). Sendo assim a deficiência em resposta às condições ambientais inerentes ao semiárido é considerada por Pimentel et al. (2002) como maior causadora de redução de produtividade das plantas, alterando suas funções fisiológicas e morfológicas.

Cada espécie apresenta diferentes níveis de tolerância ao estresse salino. O limite de tolerância depende da concentração do sal em solução, do tempo de exposição, bem como do estádio de desenvolvimento das plantas (Munns, 2002). Diante do exposto, este trabalho tem como objetivo avaliar os efeitos do estresse salino provocados pelo $\mathrm{NaCl}$ nas plantas de Physalis angulata.

\section{MATERIAL E MÉTODOS}

O experimento foi realizado na Unidade Experimental Horto Florestal, localizada em Feira de Santana-BA. Sementes de $P$. angulata foram semeadas em copos contendo substrato comercial (Plantamax $®$ ), e após 45 dias foram transferidas para vasos com capacidade para 6 litros, contendo areia lavada e solução nutritiva de Sarruge (1975), mantidas em estufa de crescimento. Para avaliação do efeito do estresse salino foi preparada solução de cloreto de sódio nas seguintes concentrações: $0 ; 50 ; 100 ; 150$ e $200 \mathrm{mM}$.

As avaliações foram realizadas 50 dias após a aplicação dos tratamentos de salinidade, onde foi analisada a massa seca (MS) da raiz, da parte área e dos frutos, após secagem em estufa a $65^{\circ} \mathrm{C}$, utilizando balança analítica de precisão. A área foliar (AF) foi mensurada com um integrador de área (Li- Cor, modelo Li-3100C). A partir dos dados de MS e AF foi calculada a razão de área foliar (RAF), área foliar especifica (AFE) e a razão de peso foliar (RPF) segundo Benincasa (2003). Foi calculada também a produtividade dos frutos levando em consideração a MS dos frutos por planta. A quantificação do teor de clorofilas foi determinada segundo metodologia proposta por Lichtenthaler (1987) com o uso do álcool 95\%. 
O delineamento experimental utilizado foi inteiramente casualizado com cinco doses de $\mathrm{NaCl}$ e quatro repetições, sendo cada constituída de seis vasos. Os resultados obtidos foram submetidos à análise de variância. O teste de Tukey foi aplicado para comparação de médias com 5\% de significância utilizando-se o software Sisvar v.5.3 (Ferreira, 2008). Para confecção dos gráficos foi utilizado o software SigmaPlot v.11.0 (Systat Software Inc., Chicago, USA).

\section{RESULTADOS E/OU DISCUSSÃO}

O estresse salino não causou redução no crescimento das plantas de $P$. angulata, observado no acúmulo de MS da raiz e da parte aérea, na área foliar e na relação raiz/parte aérea, onde não houve diferenças significativa entre os tratamentos com $\mathrm{NaCl}$. A produtividade de frutos também não foi influenciada pelos níveis de salinidade (Figura 1). A salinidade afeta não apenas o desenvolvimento, mas também a produção das culturas, efeito que se manifesta principalmente na redução da população e do desenvolvimento dos frutos, com sintomas similares ao do estresse hídrico (Rhoades et $a l .$, 2000), entretanto, isso não foi observado nesse experimento.
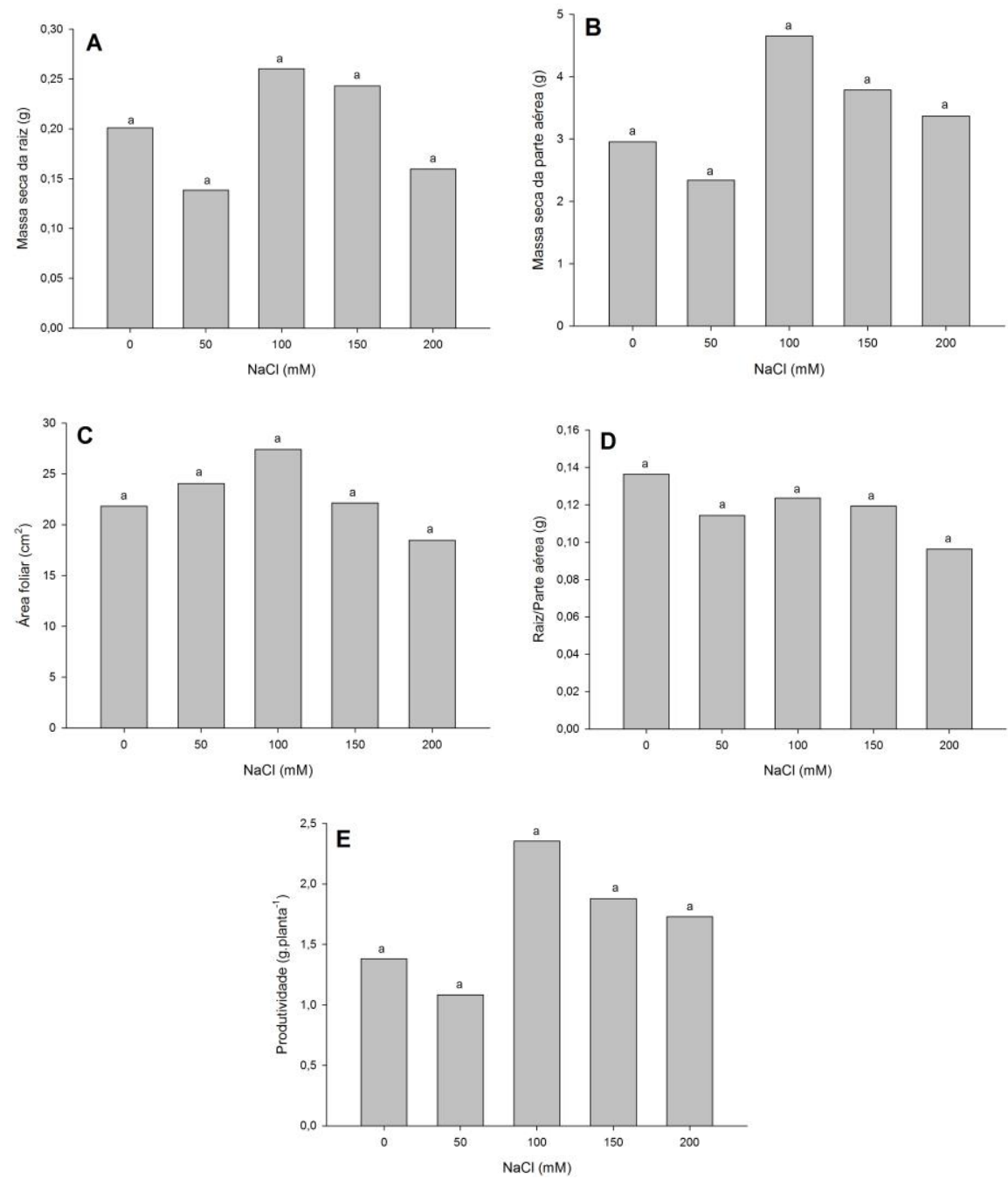

Figura 1: Massa seca da raiz (A), massa seca da parte aérea (B), área foliar (C), razão raiz/parte aérea (D) e produtividade (E) de plantas de Physalis angulata cultivadas em diferentes concentrações de solução salina. * Letras distintas diferem entre si pelo teste de Tukey $(\mathrm{p}>0,05)$. 
Para os índices fisiológicos também não foram observadas diferenças estatísticas entre os tratamentos (Figura 2), indicando que a taxa fotossintética não foi afetada pelo estresse salino, já que a área foliar disponível para a realização da fotossíntese e a espessura foliar não foi reduzida com o aumento da concentração salina, fato corroborado pelo teor de pigmentos cloroplastídicos obtidos, que foi semelhante entre os tratamentos (Tabela 1).
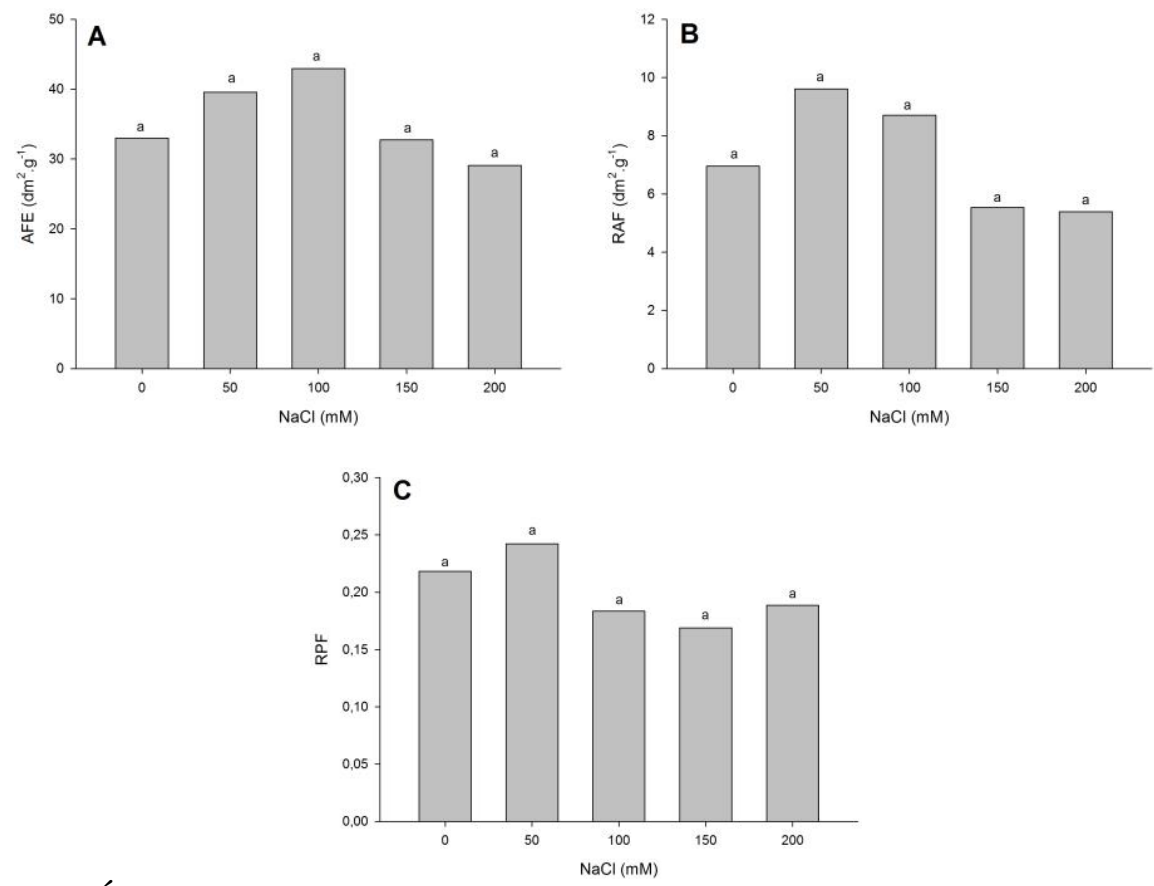

Figura 2: Área foliar específica (AFE), razão de área foliar (RAF) e razão do peso foliar (RPF) de plantas de Physalis angulata submetidas a diferentes níveis de estresse salino. * Letras distintas diferem entre si pelo teste de Tukey $(\mathrm{p}>0,05)$.

A presença de sais de sódio no solo provoca a redução do crescimento das plantas cultivadas, por reduzir o potencial osmótico da solução do solo, podendo também ocasionar toxicidade iônica, causando assim sérios prejuízos para a atividade agrícola (Munns, 2002; Flowers, 2004). Neste experimento não foi observada nenhuma influencia da salinidade no crescimento e produção de clorofila das plantas, o que poderia indicar uma tolerância da espécie. Entretanto, Souza et al. (2007) constatou que a $P$. angulata é pouco tolerante a condição de elevada salinidade com redução da massa seca da planta e comprometimento da produtividade. Souza et al. (2011) também observou a sensibilidade das sementes ao estresse salino, com redução da germinabilidade e do índice de velocidade da germinação (IVG).

Tabela 1. Teor de clorofila a, b e total $(\mathrm{a}+\mathrm{b})$ de plantas de Physalis angulata cultivadas sob diferentes concentrações de solução salina.

\begin{tabular}{cccc}
\hline $\mathbf{N a C l}(\mathbf{m M})$ & $\begin{array}{c}\text { Clorofila a } \\
\left(\mathbf{m g . c m}^{\mathbf{2}}\right)\end{array}$ & $\begin{array}{c}\text { Clorofila b } \\
\left(\mathbf{m g . c m}^{\mathbf{m}}\right)\end{array}$ & $\begin{array}{c}\text { Clorofila total } \\
\left(\mathbf{m g . c m}^{\mathbf{2}}\right)\end{array}$ \\
\hline 0 & $13,38 \mathrm{ab}$ & $21,67 \mathrm{ab}$ & $35,06 \mathrm{ab}$ \\
50 & $15,68 \mathrm{~b}$ & $25,37 \mathrm{a}$ & $41,06 \mathrm{a}$ \\
100 & $10,47 \mathrm{a}$ & $25,11 \mathrm{a}$ & $35,58 \mathrm{ab}$ \\
150 & $13,53 \mathrm{ab}$ & $23,93 \mathrm{ab}$ & $36,46 \mathrm{ab}$ \\
200 & $12,03 \mathrm{ab}$ & $19,07 \mathrm{~b}$ & $31,10 \mathrm{~b}$ \\
\hline
\end{tabular}

*Letras distintas na coluna diferem entre si pelo teste de Tukey ( $>>0,05)$. 
Mesmo com os problemas enfrentados durante a execução do experimento, como o excesso de chuvas que danificou a cobertura plástica da estufa, e a ocorrência de pragas (Figura 4), tentamos amenizar ao máximo as influências desses fatores, no entanto, pelos resultados obtidos observamos que não houve interferência dos tratamentos utilizados, necessitando de novos estudos para testar outros níveis salinos.

\section{CONSIDERAÇÕES FINAIS}

As concentrações de cloreto de sódio utilizadas não influenciaram o crescimento e o teor de pigmentos cloroplastídicos das plantas de Physalis angulata.

\section{REFERÊNCIAS}

BENINCASA, M.M.P. 2003. Análise de crescimento de plantas: noções básicas. Jaboticabal: FUNEP, 41p.

FERREIRA, D. F. 2008. SISVAR: um programa para análises e ensino de estatística. Revista Symposium, v. 6, p. 36-41.

FLOWERS, T.J. 2004. Improving crop salt tolerance. Journal of Experimental Botany, v. 55, p. 307-319.

GHEYI. H.; FAGEIRA, N. K. Efeitos dos sais sobre as plantas. In: Manejo e controle da salinidade na agricultura irrigada. Campina Grande: 1997. p. 125-131, 1997.

LECOEUR, J.; SINCLAIR, R.T. 1996. Field pea transpiration and leaf growth in response to soil water deficits. Crop Sci. v. 36, n. 2, p. 331-335.

LICHTENTHALER, H. K. 1987. Chlorophylls and carotenoids: pigments of photosynthetic biomembranes. Methods Enzymol., v. 148, p. 350- 382.

MUNNS, R. 2002. Comparative physiology of salt and water stress. Plant Cell and Environment, v. 25, p. 239-250.

PIMENTEL, C.; SARR, B.; DIOUF, O.; ABBOUD, A.C.S.; ROYMACAULEY, H. 2002. Tolerância protoplasmática foliar à seca, em dois genótipos de caupi cultivadas em campo. Rev. Univ. Rural, Série Ciências da Vida, v. 22, n. 1, p. 07-14.

RHOADES, J. D.; KANDIAH, A.; MASHALI, A. M. 2000. Uso de águas salinas para produção agrícola. Campina Grande: UFPB, 117p.

RUFATO, L. et al. 2008. Aspectos técnicos da cultura da Physalis. Florianópolis: UDESC. 100p.

SARRUGE, J.R. 1975. Soluções nutritivas. Summna Phytopathologica, v. 1, n. 3, p. 231-233.

SOUZA, M. O; SOUZA, C. L. M.; PELACANI, C. R. 20110. Germinação de sementes osmocondicionadas e não osmocondicionadas e crescimento inicial de Physalis angulata L. (Solanaceae) em ambientes salinos. Acta Botanica Brasilica, v. 25, n. 1, p. 105-112.

SOUZA, N. K. R.; ALCÂNTARA JUNIOR, J. P.; AMORIM, S. M. C. 2007. Efeito do estresse salino sobre a produção de fitomassa em Physalis angulata L. (Solanaceae). Rev. Acad., Curitiba, v. 5, n. 4, p. 379-384. 